\title{
Acute obstructive cholangitis due to fishbone in the common bile duct: a case report and review of the literature
}

\author{
Min $\mathrm{Yu}^{1 \dagger}$, Bowen Huang ${ }^{2,1+}$, Ye Lin ${ }^{1}$, Yuxue Nie ${ }^{3}$, Zixuan Zhou', Shanshan Liu² and Baohua Hou ${ }^{1,2^{*}}$ (D)
}

\begin{abstract}
Background: Choledocholithiasis is an endemic condition in the world. Although rare, foreign body migration with biliary complications needs to be considered in the differential diagnosis for patients presenting with typical symptoms even many years after cholecystectomy, EPCP, war-wound, foreign body ingestion or any other particular history before. It is of great clinical value as the present review may offer some help when dealing with choledocholithiasis caused by foreign bodies.

Case presentation: We reported a case of choledocholithiasis caused by fishbone from choledochoduodenal anastomosis regurgitation. Moreover, we showed up all the instances of choledocholithiasis caused by foreign bodies published until June 2018 and wrote the world's first literature review of foreign bodies in the bile duct of 144 cases. The findings from this case suggest that the migration of fishbone can cause various consequences, one of these, as we reported here, is as a core of gallstone and a cause of choledocholithiasis.

Conclusion: The literature review declared the choledocholithiasis caused by foreign bodies prefer the wrinkly and mainly comes from three parts: postoperative complications, foreign body ingestion, and post-war complications such as bullet injury and shrapnel wound. The Jonckheere-Terpstra test indicated the ERCP was currently the treatment of choice. It is a very singular case of choledocholithiasis caused by fishbone, and the present review is the first one concerning choledocholithiasis caused by foreign bodies all over the world.
\end{abstract}

Keywords: Choledocholithiasis, Common bile duct, Foreign body, Fishbone

\section{Background}

The incidence of gallstones is about $15 \%$ [1], and the incidence of bile-duct stones accounts for approximately $20 \%$ of all gallstones [2]. The calculus in the common bile duct (CBD) may originate from the bile duct system, known as the primary choledocholithiasis. The stones may also have been caused by the decline of stones in the gallbladder, and therefore it is called the secondary choledocholithiasis. The secondary choledocholithiasis is located in the distal of the CBD, which can cause biliary obstruction and infection. Secondary choledocholithiasis

\footnotetext{
*Correspondence: hbh1000@126.com

${ }^{+} \mathrm{Min}$ Yu and Bowen Huang contributed equally to this work.

${ }^{1}$ Department of General Surgery, Guangdong Provincial People's Hospital, Guangdong Academy of Medical Sciences, Guangzhou 510080, Guangdong, China

${ }^{2}$ The Second School of Clinical Medicine, Southern Medical University, Guangzhou 510000, Guangdong, China

Full list of author information is available at the end of the article
}

is usually considered as an extra-cystic complication of the gallbladder stones, but there are a few exceptions. For example, this paper expounded the case that fishbone entered the CBD through duodenal regurgitation. Choledocholithiasis caused by the foreign body is very rare. There hasn't been related report about the incidence so far. Choledocholithiasis is mainly manifested as abdominal pain, fever, chills, and jaundice. However, choledocholithiasis caused by the foreign body may present some specific clinical symptoms according to the nature of the foreign body, such as nausea, vomiting, and melena $[3,4]$. Primary choledocholithiasis is usually considered to be caused by the translocation of the stones from gall bladder or intrahepatic duct. Nevertheless, patients with secondary choledocholithiasis often have a history of cholecystectomy, EPCP, war-wound, foreign body ingestion, or other particular histories, which need to be paid great attention when diagnosing.

(c) The Author(s). 2019 Open Access This article is distributed under the terms of the Creative Commons Attribution 4.0 International License (http://creativecommons.org/licenses/by/4.0/), which permits unrestricted use, distribution, and 
The primary treatments for choledocholithiasis are surgery and ERCP currently, and a relatively small proportion of people adopted the methods of conservative treatment [5-7], PTC [8-12] and ESWL [13]. Herein, we report a case of choledocholithiasis caused by fishbone and review all the case reports of choledocholithiasis produced by foreign bodies. A retrospective analysis of the characteristics of the patient population, source of foreign body, clinical manifestation, treatment, and the outcome was conducted. To our knowledge, the present review was the first one concerning choledocholithiasis caused by foreign bodies and may offer some help when dealing with the peculiar secondary choledocholithiasis.

\section{Case presentation}

A 69-year-old Chinese woman with a 6-month history of remittent fever, chilling, jaundice, myalgia, fatigue, and mild headache without abdominal pain was referred to our department. The patient had undergone a BillrothII subtotal gastrectomy for the duodenal ulcer with stenosis 14 years before and cholecystectomy, T-tube choledochostomy and choledochoduodenostomy due to CBD inflammatory stenosis 10 years before. There was no tenderness in her abdomen during admission.

Blood investigations showed marked impaired liver function of TBIL $19.5 \mathrm{umol} / \mathrm{L}$, ALT $102 \mathrm{U} / \mathrm{L}$ and AST $214 \mathrm{U} / \mathrm{L}$. Markers of inflammation were shown to be elevated in patients, such as WBC $15.38 \times 10^{\wedge} 9 / \mathrm{L}$, NEU\% 88.3, procalcitonin (PCT) $4.40 \mathrm{ng} / \mathrm{ml}$ (range, 0 0.05). CA19-9 was elevated at $56.52 \mathrm{U} / \mathrm{ml}$ (range, 0-27). Ultrasonographic examination of the biliary tract showed choledocholithiasis $(4.4 \mathrm{~cm} \times 2.0 \mathrm{~cm})$ with dilatation of intrahepatic and extrahepatic bile duct (Fig. 1a). Of note, the outer layer of the stone was hyperechoic while the inner layer was hypoechoic. The strange phenomenon suggested that calculi may be made of two components at least. Then the patient underwent the upper abdominal enhanced computed tomography $(\mathrm{CT})$, and the results revealed the muddy stone in intrahepatic bile duct with dilatation and pneumatosis and showed postsubtotal gastrectomy feature. However, the most critical finding which CT revealed was a strip of hyperdense inside the CBD, which was $4.0 * 2.5 \mathrm{~cm}$ with $\mathrm{CT}$ values about 57HU (Fig. 1b, c). It was worth mentioning that the patient didn't have any past medical history about stents implantation. We diagnosed choledocholithiasis with acute obstructive cholangitis initially. However, we still didn't know the essence of the hyperdense hidden in the bile duct.

To prevent the patient from getting worse, we recommended ERC or PTC or surgery as a choice to the patient and her family. As the success ratio of ERC or PTC was decreased due to the large size of the choledocholithiasis and the surgery history, which increased the

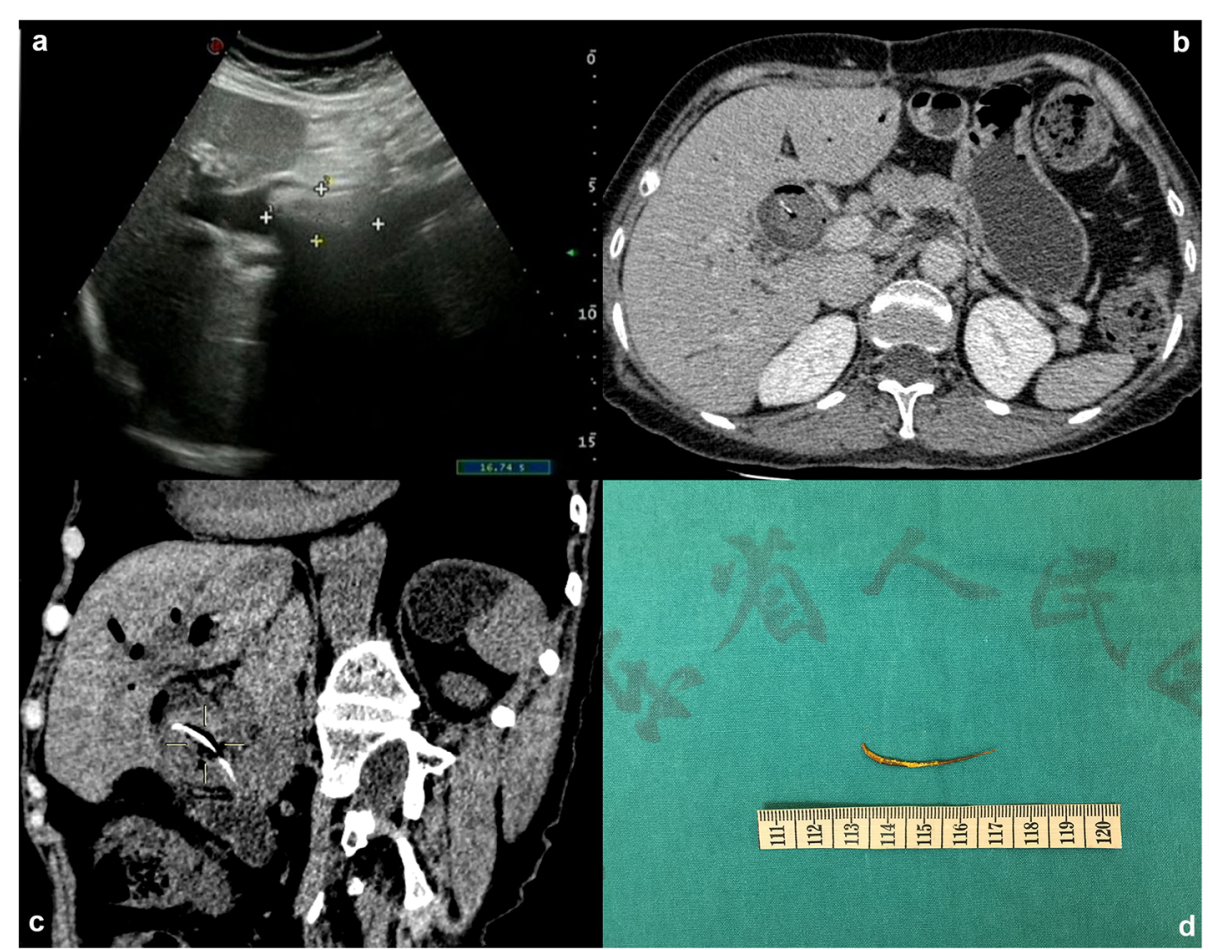

Fig. 1 Exploration and truth of the long high-density shadow. a Abdominal ultrasonography view of the biliary tract shows choledocholithiasis $(4.4 \mathrm{~cm} \times 2.0 \mathrm{~cm})$ with dilatation of intrahepatic and extrahepatic bile duct. b Plain CT scan image reveals a strip of hyperdense inside the CBD. $\mathbf{c}$ Coronal CT view of the long high-density shadow. $\mathbf{d}$ The photographs of the excised specimen showed a sharp linear fishbone 
difficulty of ERC and PTC, the patients and her family chose to perform the surgery. Under general anesthesia, laparoscopic common bile duct exploration (LCBDE) was performed on June 19, 2017. The gallbladder had been removed before, and postoperative adhesion of abdominal cavity was severe. After removed the adhesion, the dilated CBD with a diameter of $2.5 \mathrm{~cm}$ was revealed. A small incision was made into the $\mathrm{CBD}$ on the upper margin of the duodenum. Intraoperative choledochoscope revealed the massive sandy stone in the CBD.

What's more, a considerable stone about $4.0 \mathrm{~cm} \times 2.0$ $\mathrm{cm}$ with irregular shape adhered severely to the adjacent structures. The stone was extracted with a retrieval balloon and basket catheter. When we checked out the calculi removed from the bile duct, unexpectedly the stone was broken down, and we found a fishbone inside. The mass with a strip of hyperdense revealed by CT scan was a fishbone, which migrated into the CBD (Fig. 1d). The patient was uneventful when discharged on the eighth postoperative day, and without recurrence until 21 months after the operation (Additional file 1).

\section{Literature review}

We reported an unusual case of fishbone-induced choledocholithiasis. In this case, the patient's Oddi sphincter had lost function due to choledochoduodenostomy before, and the fishbone was able to pass through the choledochoduodenal anastomosis and migrate into the CBD. The fishbone acted as a core to form a mixed stone, with cholesterol as its main component ultimately.

It was secluded that the foreign body was hidden in the bile duct. These clinical manifestations always presented a diagnostic dilemma. This case's only diagnostic clue was linear and sharp calcification within the mass. However, it was hard to connect the linear calcification to the accidentally ingested fishbone because the CBD was isolated from the digestive tract in principle. Thus, identification and removal of the fishbone as soon as possible are essential.

On the other hand, the hidden foreign body in the CBD is rare and can lead to complications which include foreign body related biliary stones. Most cases have been reported as case reports. This study reviews cases of foreign body migration reported in the literature. Method searches and reviews of the literature from "PubMed" search engines using the keywords "foreign body case" and "bile duct" were carried out. Three hundred ninetyseven papers were identified, but details for only 144 cases were available for the present study [3-133]. We specified a protocol for the inclusion of the literature. First of all, the foreign body doesn't belong to the human body or isn't a parasite. Secondly, foreign body causes diseases with abnormal migration. Thirdly, the foreign body was hidden in the CBD.
The median age at diagnosed as stones caused by foreign body was 62 years old (range 5 to 91 years). The senior people (range 41 to 80 years) were too fragile to prevent the foreign body from migrating. There was no statistical significance between the genders (the male made up $47.92 \%$ versus female $51.39 \%$ ).

Details of the clinical presentations and past medical history were depicted in Table 1 . The most common clinical presentations were abdominal pain, fever/chills, and jaundice (Fig. 2a). Most of these patients had suffered cholecystectomy, and ERCP, followed by bullet injury or shrapnel wounds in third place before the foreign body induced choledocholithiasis (Fig. 2b).

There are different kinds of foreign bodies (Fig. 2c). The postoperative complications were the most common cause. The surgical clips (49 accounts for $34.0 \%$ ), stents (14 accounts for 9.7\%) and the fragment of the T-tube (12 accounts for $8.3 \%$ ) were the most CBD foreign body. There was another kind of foreign body that would pass through the human digestive tract and migrated to the CBD, which included the phytobezoar ( 9 accounts for $6.3 \%$ ), fishbone (6 accounts for $4.2 \%$ ), metal pin (3 accounts for $2.1 \%$ ), chicken bone (2 accounts for 1.4\%)and toothpick (1 accounts for $0.7 \%$ ). The third significant categories included the debris of bullet or shrapnel (18 accounts for $12.5 \%)$.

Table 1 Details of the clinical presentations and past medical history $(n=144)$

\begin{tabular}{ll}
\hline Details & $\mathrm{N}(\%)$ \\
\hline Clinical Symptoms & $108(75.0 \%)$ \\
Abdominal discomfort or abdominal pain & $58(40.3 \%)$ \\
Fever/chills & $81(56.3 \%)$ \\
Jaundice/itch & $14(9.7 \%)$ \\
Acholic stools/dark urine & $33(22.9 \%)$ \\
Nausea/vomiting & $2(1.4 \%)$ \\
Melena & $4(2.8 \%)$ \\
Asymptomatic & $12(8.3 \%)$ \\
Not mentioned & \\
Past Medical History & $83(57.6 \%)$ \\
Cholecystectomy & $31(21.5 \%)$ \\
ERCP (with sphincterotomy/Stenting) & $16(11.1 \%)$ \\
Common bile duct surgery & $9(6.3 \%)$ \\
Embolization/interventional operation & $17(11.8 \%)$ \\
Investigative laparotomy/abdominal surgery & $18(12.5 \%)$ \\
Bullet injury/shrapnel wounds & $6(4.2 \%)$ \\
Surgery/radiotherapy for carcinoma & $2(1.4 \%)$ \\
Foreign body ingestion & $2(1.4 \%)$ \\
Hydatid disease & $16(11.1 \%)$ \\
No special &
\end{tabular}




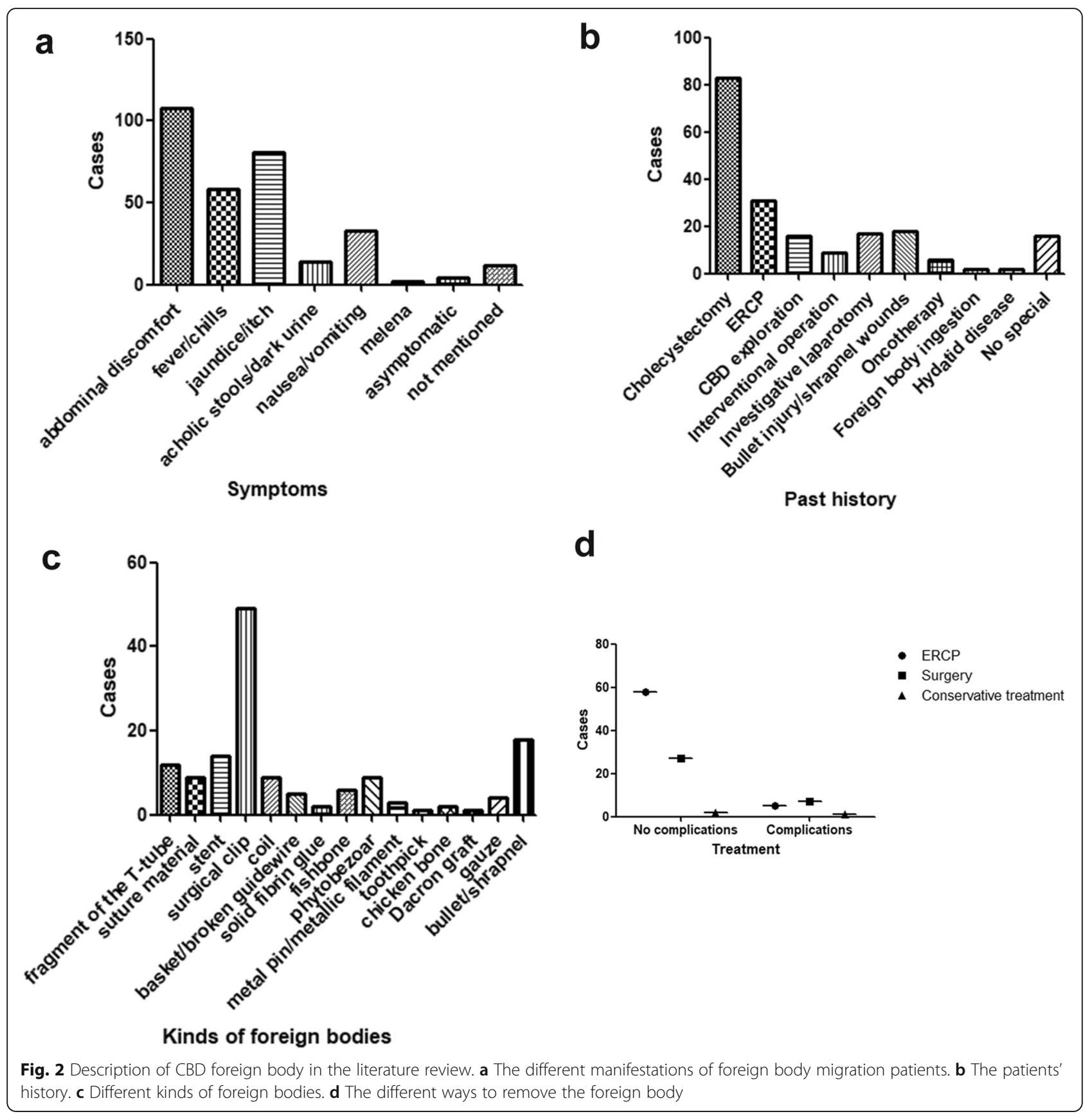

To choose the best way to remove the foreign body from the $\mathrm{CBD}$, we selected the valid data about the treatment and follow-up. After we made a nonparametric test to compare the outcome about ERCP, surgery and conservative treatment, the JonckheereTerpstra test found a significant statistical difference $(P=0.044)$ and indicated the ERCP was the best way to extract the foreign body while the surgery was chasing closely behind (Fig. 2d). Only a relatively small proportion of people used the methods of conservative treatment [5-7], PTC [8-12] and ESWL [13]. The vast majority of victims (92 accounts for $63.89 \%)$ recovered uneventfully and were perfectly well at the follow-up clinical examination, but for others the CBD foreign body migration was an omen of misfortune and disaster, it pushed through victims with long-term problems or complications, such as pancreatitis [27], recurrence of cholesterol stones [90, 92], bile leak [90, 99, 127], subhepatic abscess [127], even death $[80,81]$. 


\section{Discussion and conclusion}

Overall, the foreign body migration in the bile duct is rare. However, it is likely that the actual incidence of foreign body migration with resultant biliary complications is underestimated. It's possible that additional publications, especially in the non-English journals, non-indexed, might have been missed. What's more, cases of the foreign body hidden in the bile duct might have gone unreported or have been included as part of other types of publications.

In conclusion, although rare, foreign body migration with biliary complications need to be considered in the differential diagnosis for patients presenting with typical symptoms even many years after cholecystectomy, EPCP, war-wound, foreign body ingestion or any other particular history before. The clinical manifestations are similar to that of primary or secondary cholesterol choledocholithiasis, and ERCP is currently the treatment of choice.

This literature review was the first paper concerning on choledocholithiasis caused by foreign bodies and intended to give some suggestions about the differential diagnosis, and the options of treatment for the foreign body migrated to the CBD.

\section{Supplementary information}

Supplementary information accompanies this paper at https://doi.org/10. 1186/s12876-019-1088-8.

Additional file 1. Timeline of the case.

\begin{abstract}
Abbreviations
CBD: Common bile duct; CT: Computer tomography; ERCP: Endoscopic retrograde cholangiopancreatography; ESWL: Extracorporeal shock wave lithotripsy; LCBDE: Laparoscopic common bile duct exploration; PTC: Percutaneous transhepatic cholangio
\end{abstract}

\section{Acknowledgements}

We thank the patient for her cooperation.

\section{Authors' contributions}

$+\mathrm{MY}$ and $\mathrm{BWH}$ are contributed equally to this work. MY and BWH conceived and designed the whole project. YL, YN, ZZ, and SL collected and analyzed the data. BWH interpretation of data and drafted the article. MY gave critical revision of the article for relevant intellectual content. $\mathrm{BHH}$ had ensured the questions related to the accuracy and integrity of any part of the work. All authors have read and approved the manuscript.

\section{Funding}

This study was sponsored by grants from the Guangdong Provincial Science and Technology Plan projects (No.2016A030313769), National Natural Science Foundation of China (No.81672475), Guangzhou Science and Technology Plan of Scientific Research Projects (No.201707010323).

\section{Availability of data and materials}

All data generated or analyzed during this study are included in this published article.

\section{Ethics approval and consent to participate}

This article is a retrospective study and does not contain any studies with human subjects performed by any of the authors. So, the ethical approval was not necessary, and the Guangdong Provincial People's Hospital medical ethics committee can offer an exempt ethical statement in support.

\section{Consent for publication}

Written informed consent was obtained from the patient for publication of this case report and any accompanying images. A copy of the written consent is available for review by the editor of this journal.

\section{Competing interests}

The authors declare that they have no competing interests.

\section{Author details}

'Department of General Surgery, Guangdong Provincial People's Hospital, Guangdong Academy of Medical Sciences, Guangzhou 510080, Guangdong, China. ${ }^{2}$ The Second School of Clinical Medicine, Southern Medical University, Guangzhou 510000, Guangdong, China. ${ }^{3}$ Department of Internal Medicine, Peking Union Medical College Hospital, Beijing 100730, China.

Received: 6 November 2018 Accepted: 2 October 2019

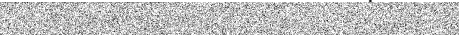

\section{References}

1. Verhart JE, Khare M, Hill M, et al. Prevalence and ethnic differences in gallbladder disease in the United States. Gastroenterology. 1999;117:632-9.

2. Ponsioen CY. Diagnosis, Differential Diagnosis, and epidemiology of primary Sclerosing cholangitis. Dig Dis. 2015;33(Suppl 2):134-9.

3. Kusters PJ, Keulen ET, Peters FP. Duodenal perforation following bile duct endoprosthesis placement. Endoscopy. 2014;46(Suppl 1 UCTN):E646-7.

4. Elewaut A, De Vos M, Huble F, et al. Unusual migration of a straight Amsterdam-type endoprosthesis for bile duct stones. Am J Gastroenterol. 1989:84:674-6.

5. Barai V, Hedawoo J, Changole S. Forgotten CBD stent (102 months) with stone-stent complex: a case report. Int J Surg Case Rep. 2017;30:162-4.

6. Girotra M, Dang SM, Rego R. Endoscopic removal of migrated vascular embolic material from the common bile duct: multi-modality approach (with video). Dig Endosc. 2014;26:492-3.

7. Onghena T, Vereecken L, Van den Dwey K, et al. Common bile duct foreign body: an unusual case. Surg Laparosc Endosc. 1992;2:8-10.

8. Carballo RL, Ruiz MI, Jimenez AR, et al. Hepatic abscesses secondary to a foreign body in the common bile duct. Rev Esp Enferm Dig. 2017;109:658.

9. Stephens M, Ruddle A, Young WT. An unusual complication of a dropped clip during laparoscopic cholecystectomy. Surg Laparosc Endosc Percutan Tech. 2010;20:e103-4

10. Kaji H, Asano N, Tamura $\mathrm{H}$, et al. Common bile duct stone caused by a fish bone: report of a case. Surg Today. 2004;34:268-71.

11. Yoshizumi T, Ikeda T, Shimizu T, et al. Clip migration causes choledocholithiasis after laparoscopic cholecystectomy. Surg Endosc. 2000; $14: 1188$.

12. O'Regan PF, Shanahan F, Lennon JR, et al. Successful endoscopic removal of a common bile duct foreign body. Endoscopy. 1982;14:26-7.

13. Hearne SE, Stump DL. Endoscopic removal of prolene sutures from the common bile duct during endoscopic retrograde cholangiography. Gastrointest Endosc. 1990:36:301-3.

14. Sakakida T, Sato H, Doi T, et al. A bile duct stone formation around a fish bone as a Nidus after Pancreatoduodenectomy. Case Rep Gastroenterol. 2018;12:69-75.

15. Zaafouri H, Hasnaoui A, Essghaeir S, et al. Ascending cholangitis secondary to migrated embolization coil of gastroduodenal artery pseudo-aneurysm a case report. BMC Surg. 2017;17:30.

16. Connell JL, Rosalki SB. Shrapnel biliary calculus; a case report. Br J Surg. 1954;42:218-9.

17. Hurt RL. Penetrating chest wound with lodgement of the foreign body in the common bileduct; case report. Br J Surg. 1947;34:429.

18. Brunaldi VO, Brunaldi MO, Masagao R, et al. Toothpick inside the common bile duct: a case report and literature review. Case Rep Med. 2017;2017:1-4.

19. Ribeiro I, Pinho R, Proenca $L$, et al. A strange finding in the common bile duct. Gastroenterol Hepatol. 2016;39:531-2.

20. Bent CK, Wright L, Dong PR. "Coildocholithiasis"-common bile duct obstruction secondary to migration of right hepatic artery Pseudoaneurysm coils. J Vasc Interv Radiol. 2016;27:1741-3.

21. Patil U, Dhonde A. Endoscopic management of an unusual foreign body in the bile duct. Gastrointest Endosc. 2016;83:1288-9.

22. Albert JG. "Cutting the wire" as a troubleshooter for a Dormia basket impacted in the common bile duct. Gastrointest Endosc. 2016;83:465. 
23. Yang YL, Zhang C, Zhang HW, et al. Common bile duct injury by fibrin glue: report of a rare complication. World J Gastroenterol. 2015;21:2854-7.

24. Upwanshi MH, Shaikh ST, Ghetla SR, et al. De novo Choledocholithiasis in retained common bile duct stent. J Clin Diagn Res. 2015;9:D17-8.

25. Sormaz IC, Keskin M, Sonmez RE, et al. Obstructive jaundice secondary to endoclip migration into common bile duct after laparoscopic cholecystectomy. Minerva Chir. 2015;70:381-3.

26. Hong $T, X u X Q, H e X D$, et al. Choledochoduodenal fistula caused by migration of endoclip after laparoscopic cholecystectomy. World J Gastroenterol. 2014;20:4827-9.

27. Ghalim F, Alatawi A, Leblanc S, et al. Endoscopic retrograde cholangioscopic removal of migrated vascular coils from the common bile duct. Clin Res Hepatol Gastroenterol. 2014;38:e31-2.

28. Fernandez-Urien I, Marra-Lopez C, Jimenez J. A rare cause of biliary colics. Gastroenterology. 2014;147:e9-10.

29. Garcia-Gallont R, Velasquez JS, Duarte W. Surgical removal of a severed Dormia basket from the bile duct. Endoscopy. 2014;46(Suppl 1 UCTN):E20-1.

30. Ray S, Bhattacharya SP. Endoclip migration into the common bile duct with stone formation: a rare complication after laparoscopic cholecystectomy. JSLS. 2013;17:330-2.

31. Zapatier JA, Jani P, Pimentel R, et al. Pancreatic stent migration into the bile duct causing cholangitis. Endoscopy. 2013;45(Suppl 2):E324-5.

32. Bartos D, Bartos A, Acalovschi l, et al. Biliary plastic stent as a matrix core for lithogenesis in the common bile duct: a rare cause of jaundice. J Gastrointestin Liver Dis. 2012;21:427-9.

33. Rowe D, Nikfarjam M. Cystic duct clip migration into the common bile duct. Indian J Gastroenterol. 2012;31:86

34. AlGhamdi HS, Saeed MA, AlTamimi AR, et al. Endoscopic extraction of vascular embolization coils that have migrated into the biliary tract in a liver transplant recipient. Dig Endosc. 2012;24:462-5.

35. Dias R, Dharmaratne P. Ingested foreign body in the common bile duct. J Indian Assoc Pediatr Surg. 2012;17:31-2.

36. Sajith KG, Dutta AK, Joseph AJ, et al. Tombstone of surgical clip in common bile duct. Trop Gastroenterol. 2012;33:67-9.

37. Bhandari $\mathrm{V}$, Singh $\mathrm{M}$, Vyas $\mathrm{HG}$, et al. Diagnostic dilemma in an unusual case of common bile duct obstruction. Gut Liver. 2011;5:245-7.

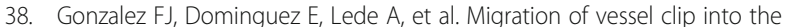
common bile duct and late formation of choledocholithiasis after laparoscopic cholecystectomy. Am J Surg. 2011;202:e41-3.

39. Gorman DR, Hutson WR. Successful endoscopic removal of metal vascular coils from the biliary tree. Dig Liver Dis. 2011;43:e27.

40. Altun R, Yildirim AE, Ocal S, et al. Coil migration into the common bile duct as a cause of cholangitis. Endoscopy. 2011;43(Suppl 2 UCTN):E33.

41. Martos M, Cosme A, Bujanda L, et al. Obstructive jaundice for biliary mold due to foreign body. Rev Esp Enferm Dig. 2011;103:36-7.

42. Lee SL, Kim HK, Cho YS. Acute obstructive cholangitis due to foreign body in the common bile duct. Migrated endoclip. Gastroenterology. 2010;139:e3-4.

43. Ransibrahmanakul K, Hasyagar C, Prindiville T. Removal of bile duct foreign body by using spyglass and spybite. Clin Gastroenterol Hepatol. 2010;8:e9.

44. Teicher EJ, Sandhu RS, Dangleben DA, et al. Common duct obstruction by shotgun bullet fragment as a cause of cholangitis. Am Surg. 2010;76:780-2.

45. Somi MH, Rezaeifar P. Shrapnel splinter in the common bile duct. Arch Iran Med. 2010;13:53-6.

46. Das K, Basu K, Ray $\mathrm{S}$, et al. Suture material in the common bile duct causing recurrent post-cholecystectomy pain. Endoscopy. 2010;42(Suppl 2):E258.

47. Dokas S, Kalampakas A, Delivorias $\mathrm{P}$, et al. Removal of a large stone growing around and encasing a plastic biliary stent: respect the ductal axis. Dig Liver Dis. 2009;41:319-21.

48. Bansal VK, Misra MC, Bhowate P, et al. Laparoscopic management of common bile duct "Stentolith". Trop Gastroenterol. 2009;30:95-6.

49. Goshi T, Okamura S, Takeuchi H, et al. Migrated endoclip and stone formation after cholecystectomy: a case treated by endoscopic sphincterotomy. Intern Med. 2009:48:2015-7.

50. Hoffman A, Kiesslich R, Galle PR, et al. A 9-year retained T-tube fragment encased within a stone as a rare cause of jaundice. Z Gastroenterol. 2008;46:700.

51. Kim KH, Jang BI, Kim TN. A common bile duct stone formed by suture material after open cholecystectomy. Korean J Intern Med. 2007;22:279-82.

52. Tsujino T, Sugawara $Y$, Kawabe T, et al. Foreign body (suture thread) in the bile duct after living donor liver transplantation. Liver Transpl. 2007;13:1065-6.

53. Steffen M, Kronsbein $H$, Wesche L. Metal clip as a nidus for formation of common bile duct stone following laparascopic cholecystectomy. Z Gastroenterol. 2007;45:317-9.
54. Dolay K, Alis H, Soylu A, et al. Migrated endoclip and stone formation after cholecystectomy: a new danger of acute pancreatitis. World J Gastroenterol. 2007;13:6446-8

55. Li ZS, Liao Z. A simple method to remove an embedded self-expandable metallic stent with a balloon. Endoscopy. 2007;39(Suppl 1):E233-4.

56. Mangiavillano B, Masci E. An obstructive, proximally migrated plastic biliary stent extracted with a "modified" Seldinger technique and a polypectomy snare. Endoscopy. 2007;39(Suppl 1):E256.

57. Kim TO, Lee $\mathrm{SH}, \mathrm{Kim} \mathrm{GH}$, et al. Common bile duct stone caused by a phytobezoar. Gastrointest Endosc. 2006;63:324.

58. Aloysius MM, Zaitoun AM, Goddard WP, et al. EUS-guided core biopsy for pseudopapillary tumor of the pancreas. Gastrointest Endosc. 2006;63:155-6.

59. Cimsit B, Keskin M, Ozden I, et al. Obstructive jaundice due to a textiloma mimicking a common bile duct stone. J Hepato-Biliary-Pancreat Surg. 2006; 13:172-3.

60. Alsulaiman R, Barkun J, Barkun A. Surgical clip migration into the common bile duct after orthotopic liver transplantation. Gastrointest Endosc. 2006;64: 833-4.

61. Turaga KK, Amirlac B, Davis RE, Yousef K, Richards A, Fitzgibbons RJ Jr. Cholangitis after coil embolization of an iatrogenic hepatic artery Pseudoaneurysm: unusual case report. Surg Laparosc Endosc Percutan Tech. 2006;16:36-8

62. Moghaddam JA, Amini M, Adibnejad S. Development of bile duct bezoars following cholecystectomy caused by choledochoduodenal fistula formation: a case report. BMC Gastroenterol. 2006;6:1.

63. Zuber-Jerger I, Kullmann F. Prevention of food bezoar in the common bile duct by endoscopic stenting. Dig Liver Dis. 2006;38:529-30.

64. Mouzas IA, Petrakis I, Vardas E, et al. Bile leakage presenting as acute abdomen due to a stone created around a migrated surgical clip. Med Sci Monit. 2005;11:S16-8.

65. Kamona A, Mansour A, Qandeel M, et al. Biliary obstruction secondary to combat-related foreign bodies: report of two cases. Abdom Imaging. 2005; 30:748-9.

66. Sandroussi C, Lemech LD, Grunewald B, et al. Late complication following coil embolization of a biliary leak. ANZ J Surg. 2005;75:614-5.

67. Chong VH, Yim HB, Lim CC. Clip-induced biliary stone. Singap Med J. 2004; 45:533-5.

68. Kim YH, Kim YJ, Park WK, et al. Fish bone as a nidus for stone formation in the common bile duct: report of two cases. Korean J Radiol. 2004;5:210-3.

69. Dell'Abate $\mathrm{P}$, Del RP, Soliani $\mathrm{P}$, et al. Choledocholithiasis caused by migration of a surgical clip after video laparoscopic cholecystectomy. J Laparoendosc Adv Surg Tech A. 2003;13:203-4.

70. Eguchi S, Matsuo S, Hidaka M, et al. Impaction of a shrapnel splinter in the common bile duct after migrating from the right thoracic cavity: report of a case. Surg Today. 2002:32:383-5.

71. Lindstrom E, Ohlsson B, Robertson F, et al. Pin within a bile duct stone. Gastrointest Endosc. 2002;55:912.

72. Haq A, Morris J, Goddard C, et al. Delayed cholangitis resulting from a retained T-tube fragment encased within a stone: a rare complication. Surg Endosc. 2002;16:714

73. Tsumura H, Ichikawa $\mathrm{T}$, Kagawa $\mathrm{T}$, et al. Failure of endoscopic removal of common bile duct stones due to endo-clip migration following laparoscopic cholecystectomy. J Hepato-Biliary-Pancreat Surg. 2002;9:274-7.

74. Froehlich F, Nussbaumer F, Worreth M. Broken T-tube branch causing bile duct stone. Gastrointest Endosc. 2001:54:494-5.

75. Matsumoto H, Ikeda E, Mitsunaga S, et al. Choledochal stenosis and lithiasis caused by penetration and migration of surgical metal clips. J HepatoBiliary-Pancreat Surg. 2000;7:603-5.

76. Baldota S, Breach C, Murtuza B, et al. Chicken bone injury of the common bile duct. J R Soc Med. 2000;93:84.

77. Bayar S, Saxena R, Salem RR. Foreign body reaction to a metal clip causing a benign bile duct stricture 16 years after open cholecystectomy: report of a case. Surg Today. 2000;30:534-6.

78. Hatzidakis AA, Karampekios S, Tsetis D, et al. Percutaneous foreign body retrieval through the biliary tract with the Nitinol goose-neck snare. Eur Radiol. 2000;10:1355.

79. Ng WT, Kong CK, Lee WM. Migration of three endoclips following laparoscopic cholecystectomy. J R Coll Surg Edinb. 1999;44:200-2.

80. Alberts MS, Fenoglio M, Ratzer E. Recurrent common bile duct stones containing metallic clips following laparoscopic common bile duct exploration. J Laparoendosc Adv Surg Tech A. 1999;9:441-4. 
81. Simmons TC, Essilfie W, Fleming A. Obstructive jaundice occurring 40 months after gunshot wound to the left thoraco-abdomen. Gastrointest Endosc. 1998;48:423-5.

82. Loveday EJ. A migrating biliary wallstent: an unusual complication. Clin Radiol. 1997:52:246.

83. Pescatore P, Meier-Willersen HJ, Manegold BC. A severe complication of the new self-expanding spiral nitinol biliary stent. Endoscopy. 1997;29:413-5.

84. Cetta F, Lombardo F, Baldi C. Clip migration within the common duct after laparoscopic cholecystectomy a case of transient acute pancreatitis in the absence of a source. Endoscopy. 1997;29:S59-60.

85. Muhammad SR, Gatehouse D. Removal of a retained T-tube from the common bile duct. J Pak Med Assoc. 1997;47:194-5.

86. Schutz SM, Chinea C, Friedrichs P. Successful endoscopic removal of a severed, impacted Dormia basket. Am J Gastroenterol. 1997:92:679-81.

87. Bradfield H, Granke D. Surgical clip as a nidus for a common bile duct stone: radiographic demonstration. Abdom Imaging. 1997;22:293-4.

88. Shibata S, Okumichi T, Kimura A, et al. A case of choledocholithiasis with an endoclip nidus, 6 months after laparoscopic cholecystectomy. Surg Endosc. 1996;10:1097-8.

89. Brogdon BG, Neuffer FH, Siner JR. Choledochal 'clipoliths' after cholecystectomy. South Med J. 1996;89:1111-3.

90. Savader SJ, Brodkin J, Osterman FJ. In situ formation of a loop snare for retrieval of a foreign body without a free end. Cardiovasc Intervent Radiol. 1996;19:298-301.

91. Entel RJ, Peebles MW. Migratory surgical clip in the common bile duct: CT diagnosis. Abdom Imaging. 1996;21:329-30.

92. Silvis SE, Meier PB, Nelson DB. The use of a wire mesh stent in treating biliary obstruction caused by shrapnel. Gastrointest Endosc. 1996:44:741-6.

93. Lamotte $M$, Kockx M, Hautekeete $M$, et al. Biliary phytobezoar: a medical curiosity. Am J Gastroenterol. 1995;90:1346-8.

94. Tsai CC, Mo LR, Lin RC, et al. Delayed spontaneous migration of GianturcoRosch metallic stent from the biliary tree. Eur J Radiol. 1995;20:221-3.

95. Martinez J, Combs W, Brady PG. Surgical clips as a nidus for biliary stone formation: diagnosis and therapy. Am J Gastroenterol. 1995;90:1521-4.

96. Rizzo J, Tripodi J, Gold B, et al. Surgical clips as a nidus for stone formation in the common bile duct. J Clin Gastroenterol. 1995;21:169-71.

97. Szanto I, Gamal EM, Banai J, et al. Common bile duct stone formation induced by tomato skin following endoscopic sphincterotomy. Endoscopy. 1994:26:712.

98. Thors H, Gudjonsson H, Oddsson E, et al. Endoscopic retrieval of a biliary Ttube remnant. Gastrointest Endosc. 1994:40:241-2.

99. Uomo G, Manes G, Laccetti M, et al. Necrotizing acute pancreatitis due to a common bile duct foreign body. Am J Gastroenterol. 1994;89:1109-10.

100. Benakis P, Nicolakis D, Triantafillidis JK. Successful endoscopic removal of part of a T-tube from the common bile duct. Endoscopy. 1994;26:756.

101. Sato T, Denno R, Yuyama Y, et al. Unusual complications caused by endoclip migration following a laparoscopic cholecystectomy: report of a case. Surg Today. 1994;24:360-2.

102. Kelly MD, Hugh TB. Cherry stalk in the common bile duct. Aust N Z J Surg. 1993:63:571-4

103. Arnaud JP, Bergamaschi R. Migration and slipping of metal clips after celioscopic cholecystectomy. Surg Laparosc Endosc. 1993;3:487-8.

104. Mansvelt B, Harb J, Farkas B, et al. "Clip-stone" filiation within the biliary tract. HPB Surg. 1993:6:185-8.

105. Wu WC, Katon RM, JH MA. Endoscopic management of common bile duct stones resulting from metallic surgical clips (eat's eye calculi). Gastrointest Endosc. 1993:39:712-5.

106. Cetta F, Lombardo F, Rossi S. Large foreign body as a nidus for a common duct stone in a patient without spontaneous biliary enteric fistula or previous abdominal surgery. HPB Surg. 1993;6:235-42.

107. Gay P, Gaddie D. Perforation of the stomach by fish bone producing delayed transient obstructive jaundice. Aust N Z J Surg. 1993;63:826-7.

108. Raoul JL, Bretagne JF, Siproudhis L, et al. Cystic duct clip migration into the common bile duct: a complication of laparoscopic cholecystectomy treated by endoscopic biliary sphincterotomy. Gastrointest Endosc. 1992;38:608-11.

109. Matsuura T, Kanisawa Y, Sato T, et al. Migration of "endo-clips" into common bile-duct after laparoscopic cholecystectomy. Lancet. 1992;340:306.

110. Ghazanfari K, Gollapudi PR, Konicek FJ, et al. Surgical clip as a nidus for common bile duct stone formation and successful endoscopic therapy. Gastrointest Endosc. 1992;38:611-3.

111. Mitchell R, Kerr R, Barton J, et al. Biliary obstruction secondary to shrapnel. Am J Gastroenterol. 1991;86:1531-4.
112. David X, Bories P, Parelon G, et al. Acute pancreatitis induced by "herbs of Provence". Lancet. 1991;337:311.

113. Cardin F, Fritsch J, Aubert A, et al. Two-stage endoscopic removal of a foreign body from the common bile duct. Surg Endosc. 1991;5:94-5.

114. Goh PM, Sim EK, Isaac JR. Endoscopic extraction of a proximally migrated Amsterdam-type biliary endoprosthesis. Gastrointest Endosc. 1990;36:539-40.

115. Banez VP, Leung JW, Lau WY. Endoscopic management of an unusual intrabiliary foreign body. Br J Surg. 1990;77:882.

116. Sakai $P$, Ishioka $S$, Zambrano M, et al. Endoscopic removal of an atypical common bile duct foreign body. Endoscopy. 1990;22:93.

117. Janson JA, Cotton PB. Endoscopic treatment of a bile duct stone containing a surgical staple. HPB Surg. 1990;3:67-71.

118. Merrett M, Desmond P. Removal of impacted endoscopic basket and stone from the common bile duct by extracorporeal shock waves. Endoscopy. 1990:22:92.

119. Ormann W. A thread as a nidus of a common bile duct calculus--findings during endoscopic lithotripsy. Endoscopy. 1989;21:191-2.

120. Niebuhr $H$, Nowak $H$, Tichbi E. A grenade splinter as the cause of cholangitis and icterus. Dtsch Med Wochenschr. 1989;114:1283-5.

121. Davis M, Hart B, Kleinman R. Obstructive jaundice from open vessel clip. Gastrointest Radiol. 1988;13:259-60.

122. Orda R, Leviav A, Ratan I. Common bile duct stone caused by a foreign body. J Clin Gastroenterol. 1986;8:466-8.

123. Danzi JT. Two cases of acute pancreatitis due to a foreign body. Gastrointest Endosc. 1986;32:360-1.

124. Rudiger E, Weiss E, Schludermann W. Postoperative complications of gallbladder stones. Endoscopy. 1985;17:85.

125. Siegel JH. Biliary bezoar: the sump syndrome and choledochoenterostomy. Endoscopy. 1982;14:238.

126. Edwards FH, Davies RS. Late post-traumatic obstructive jaundice secondary to a biliary tract foreign body. J Trauma. 1982;22:336-8.

127. Brutvan FM, Kampschroer BH, Parker HW. Vessel clip as a nidus for formation of common bile duct stone. Gastrointest Endosc. 1982;28:222-3.

128. Klein E, Schneebaum S, Feuchtwanger MM, et al. Shell splinter in the common bile duct: a rare cause of obstructive jaundice. Am J Surg. 1981; 141:376-7.

129. Rao BK, Lieberman LM. Intermittent common bile duct obstruction at ampulla of Vater due to chicken bone impaction: diagnosis by hepatobiliary imaging. Clin Nucl Med. 1981;6:59-61.

130. Prinz RA, Pickleman J. Common bile duct obstruction associated with a dacron H-graft portacaval shunt. Arch Surg. 1978;113:333-5.

131. Weithofer G, Blazek Z, Warm K, et al. Spontaneous expulsion of a migrating infantry missile impacted in the duodenum and the common bile duct, 32 years after wounding. Endoscopy. 1977;9:106-9.

132. Rhomberg HP, Judmair G, Bodner E. Grenade splinter causing biliary colic. Lancet. 1977;1:201.

133. Krontiris A, Tsironis A. Common duct obstruction by a bullet compression cap: a rare case. Ann Surg. 1962;156:303-6.

\section{Publisher's Note}

Springer Nature remains neutral with regard to jurisdictional claims in published maps and institutional affiliations.

Ready to submit your research? Choose BMC and benefit from:

- fast, convenient online submission

- thorough peer review by experienced researchers in your field

- rapid publication on acceptance

- support for research data, including large and complex data types

- gold Open Access which fosters wider collaboration and increased citations

- maximum visibility for your research: over $100 \mathrm{M}$ website views per year

At BMC, research is always in progress.

Learn more biomedcentral.com/submissions 